\title{
Modeling and Analysis of Energy/Exergy for Absorber Pipes of Linear Parabolic Concentrating Systems
}

\author{
Reza Alayi $\mathbb{D}^{1},{ }^{1}$ Mahdi Mohkam, ${ }^{2}$ Hossein Monfared, ${ }^{3}$ Alibek Issakhov, ${ }^{4}$ \\ and Nima Khalilpoor $\mathbb{B}^{5}$ \\ ${ }^{1}$ Department of Mechanics, Germi Branch, Islamic Azad University, Germi, Iran \\ ${ }^{2}$ Department of Renewable Energy and Energy Conversion, Institute of Science and High Technology and Environmental Sciences, \\ Graduate University of Advanced Technology, Kerman, Iran \\ ${ }^{3}$ Department of Mathematics, Germi Branch, Islamic Azad University, Germi, Iran \\ ${ }^{4}$ Faculty of Mechanics and Mathematics, Department of Mathematical and Computer Modelling, Al-Farabi Kazakh \\ National University, Almaty, Kazakhstan \\ ${ }^{5}$ Department of Energy Engineering, Graduate School of the Environment and Energy, Science and Research Branch, \\ Islamic Azad University, Tehran, Iran
}

Correspondence should be addressed to Reza Alayi; reza.alayi@yahoo.com and Nima Khalilpoor; nimakhalilpoor@gmail.com

Received 28 May 2021; Revised 23 August 2021; Accepted 28 October 2021; Published 11 November 2021

Academic Editor: Alberto Alvarez

Copyright (c) 2021 Reza Alayi et al. This is an open access article distributed under the Creative Commons Attribution License, which permits unrestricted use, distribution, and reproduction in any medium, provided the original work is properly cited.

In this paper, the physical parameters of the absorber pipe of a linear parabolic collector have been investigated. The types of solar collectors, specifically the linear parabolic collector, have been comprehensively studied. Then, the mathematical model of heat transfer in the absorber pipe of the collector has been presented based on valid references. Numerical solutions of the equations related to the absorber pipe were performed by MATLAB software, and the effects of the physical parameters of the absorber pipe on its efficiency were investigated. The results show that increasing the length of the absorber pipe causes a nonlinear decrease in the efficiency of the absorber pipe. One of the important results is the increase in fluid temperature due to the increase in the diameter of the adsorbent tube, which increases the diameter of the fluid temperature by $60 \mathrm{~K}$, in which the parameter increases the efficiency by $0.38 \%$.

\section{Introduction}

At present, solar power plant technology using a linear parabolic concentrator is the most significant method among thermal-electric methods for renewable energy production $[1,2]$. Figure 1 shows a linear parabolic power plant that was first used in 1984 in a desert close to California, USA. Later, this technology (both solar and hybrid) was used in countries such as Spain, Egypt, Morocco, and the UAE. These power plants, which operate on the basis of daily weather characteristics, generate about 14 to $80 \mathrm{MW}$ of electricity [3-5]. In Iran, researches and studies have been conducted in the field of these power plants, and a power plant with a capacity of $350 \mathrm{~kW}$ for research purposes has been built in Shiraz by the Renewable Energy and Energy Efficiency Organization of Iran $[6,7]$.

The technical and scientific developments gained as a result of the implementation of the Shiraz solar power plant project makes Iran one of the few countries producing solar power plants of the linear parabolic concentrator type [8-10].

These plants include parallel and long rows of collectors. Due to the geometric structure of the collectors of this power plant, direct sunlight should be reflected in its linear center. With a concentration coefficient of solar radiation between 2 and 40 , the temperature can reach $400^{\circ} \mathrm{C}$ in the center of the collectors [11-13]. Each set of linear parabolic collectors may be 5 to $6 \mathrm{~m}$ wide, 1 to $2 \mathrm{~m}$ high, and more than $150 \mathrm{~m}$ 


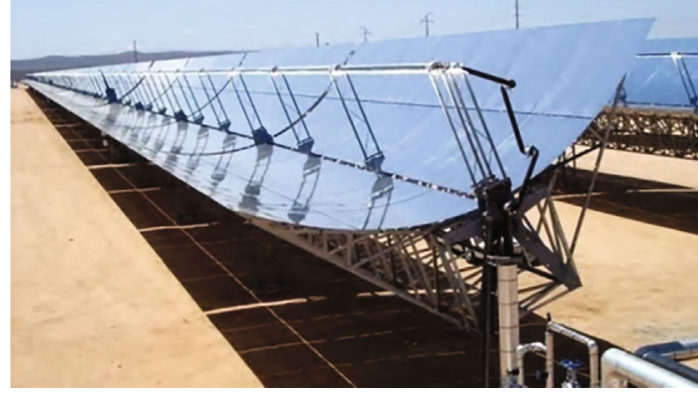

Figure 1: Linear parabolic power plant [6].

long. A large number of these complexes are needed to supply the energy of the power plant. For example, a power plant in California with a capacity of $30 \mathrm{MW}$ uses 490 collectors. These collectors occupy a large part of the power plant space and their cost of repair and maintenance has a great impact on the economic aspects of the power plant [14-16].

Most parts of concentrators consist of parabolic reflective surfaces made of glass mirrors mounted on a retaining structure and aligned north-south. These surfaces reflect and focus sunlight in their focal line. The first generations of linear parabolic surfaces were made of $4 \mathrm{~mm}$ glass which was heavy and expensive. Recently, new advances have been made to reduce costs and weight and use new methods and materials such as polished aluminum instead of glass mirrors [17-19].

The receiver used in this power plant consists of absorber pipes, which are usually made of black-coated metal and a protective layer of glass. They are placed along the focal line to be able to absorb the most energy and withstand high temperatures. To increase the efficiency of the absorber pipe, its surface is covered with a metal oxide, which has a high coefficient, and also, the glass pipe is covered with a wrapper to prevent heat loss and radiation loss [20-22].

Black chrome, black nickel, and cermets are common coatings. Cermet coatings have good stability at high temperatures. Black nickel has a higher absorption coefficient and lower price than cermet but is limited to operating temperatures below $300^{\circ} \mathrm{C}[23,24]$.

Previous research in this area includes the following: Cao et al. [25] conducted a study on thermal/frictional performance of a spiral pipe with a ring-shaped depression used as an in-pond heat exchanger. In 20212, Liu et al. [26] conducted a CFD-based irreversibility analysis of avant-garde semi-O/O-shape grooving fashions of a solar pond heat trade-off unit. In 2021, Jafary et al. [27] published an article titled "A Complete Energetic and Exergetic Analysis of a Solar Powered Trigeneration System with Two Novel Organic Rankine Cycle (ORC) Configurations."

In this research, the exergy analysis of solar concentrating power plants is performed. The optimization of the solar concentrator system of linear parabolic type has been done by considering the physical parameters of the absorber pipe.

\section{Methods and Materials}

A linear parabolic collector is a simple parabolic mirror that diverts the sun's rays from its natural axis to its own axis.
The curvature radius of these mirrors is about 1 to 4 times the focal length, and the typical focus ratio is about 80 , but with larger scales, this value can be even greater. This parabolic mirror is placed along the axis, which is, in fact, the parabolic focal line. A collector called an absorber pipe is installed at the location of the axis. Mirrors and pipes are mounted on a steel structure to hold them firmly in place (see Figure 2). This structure follows the sun from east to west every day to ensure that the sun's rays reach the linear receiver.

The liquid inside the absorber pipe (usually combined oil) heats up, so the stored energy is discharged to the heat exchanger through the circulation of this liquid. The discharged energy is given to the water in a typical steam cycle (Rankin), a process called indirect steam generation, which is in two stages. There is another method, which is a onestage method, in which water is used directly.

2.1. Modeling Parabolic Concentrator. The cross-section perpendicular to the concentrator axis is in the form of a parabola. Considering Figure 1, which shows the concentrator cross section in $x-y$ coordinates, the parabolic equation is [18-20]

$$
y=\frac{x^{2}}{4 a} .
$$

$a$ is the focal length of the parabola and the distance from the focal point to the parabolic axis which is the origin of the coordinates. $\varphi_{r}$ is the angle of the parabolic circumference and is the angle between the vertical and linear axis that connects the focal point to the edge. If a line is drawn from the center of the parabola to any point of it, the angle between the vertical axis and this line is denoted by $\varphi$ and varies from zero to $\varphi_{r}$. The width of the aperture of the concentrator is $w$, so the coordinates of the edge of the concentrator are obtained according to the following equation:

$$
\left\{\begin{array}{l}
\left.x\right|_{\varphi=\varphi_{r}}=\frac{w}{2}, \\
\left.y\right|_{\varphi=\varphi_{r}}=\frac{w^{2}}{16 a} .
\end{array}\right.
$$

By knowing $\varphi_{r}$ and $w$, we can always get the focal length of the parabola and the parabola equation is determined according to Figure 2:

$$
\tan \varphi_{r}=\frac{x}{a-y} .
$$

By placing the values of $y$ and $x$ from equation (2) into equation (3), finally, the focal length of the parabola is obtained as follows [9-20]:

$$
a=\frac{w\left(1 \pm \sqrt{1+\tan ^{2} \varphi_{r}}\right)}{8 \tan \varphi_{r}} .
$$

In the above equation, the positive sign for $\varphi_{r} \leq 90^{\circ}$ and 


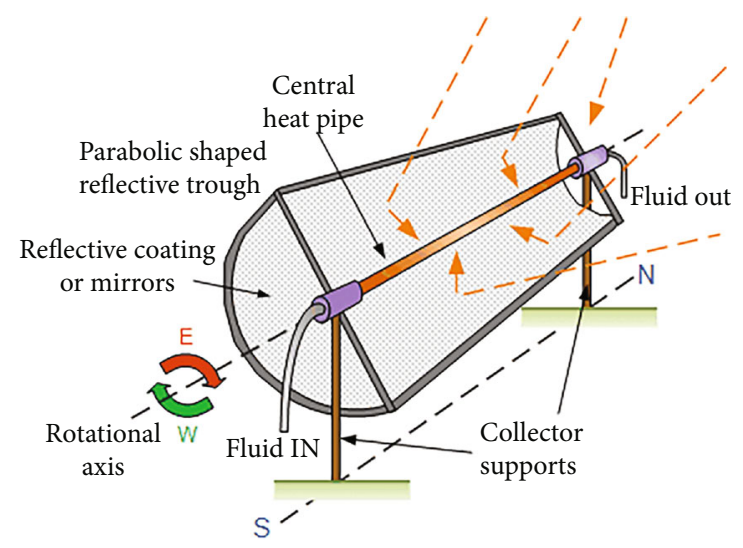

Figure 2: Sunlight and its reflection [9].

TABLE 1: Model validation with thermal efficiency.

\begin{tabular}{lccc}
\hline $\begin{array}{l}\text { Length of absorber } \\
\text { pipe }(\mathrm{m})\end{array}$ & $\eta_{\text {total }}(\%)[9]$ & $\eta_{\text {total }}(\%)$ & Deviation (\%) \\
\hline 3 & 50 & 65 & 9 \\
4 & 55.6 & 50 & 11 \\
5 & 40.2 & 40 & 0.5 \\
\hline
\end{tabular}

the negative sign for $\varphi_{r}>90^{\circ}$ are used. Another geometric parameter that is important in the equations of the concentrators is the concentration ratio. This parameter is denoted by $c$ and is the area of the surface of the concentrator aperture to the area of the surface of the absorber pipe. Given that the width of the concentrator is $w$, its length is $L$, and the outer diameter of the absorber tube is $D$, the concentration ratio is as follows:

$$
C=\frac{\left(W-D_{O}\right)}{\pi D_{O}} .
$$

The total area of the parabolic concentrator is the area of the collector aperture from which the sunlight enters the concentrator and is obtained by multiplying the length by the width of the collector [9]:

$$
A_{C}=W \cdot L
$$

2.2. Radiation Flux Absorbed by the Absorber Pipe. To calculate the flux absorbed by the outer surface of the metal pipe, the radiative properties of the surfaces as well as the coefficient of radiation received by the absorber pipe due to the optical losses of the concentrator must be known. The length of the element is $d x$ and the fluid enters with temperature $T$ and leaves with temperature $T+d T$. The average temperature of the outer surface of the absorber pipe is assumed to be $T_{P}$ and the average temperature of its glass coating is assumed to be $T_{C}$, and $T_{a}$ is the ambient temperature.

The solar flux, denoted by $I_{b}$, enters the collector perpendicular to the surface of the concentrator. Part of this radiative flux is lost due to optical losses as well as the radiative properties of the surfaces, and the rest is absorbed by the outer surface of the absorber pipe.

When the flux $I_{b}$ enters the surface of the collector aperture, a small part of it is absorbed by the metal pipe when hitting the absorber pipe. A large amount of it after passing the aperture of the concentrator hits the parabolic mirror and, after reflecting from the mirror reflection, concentrates on the absorber pipe. The amount of radiation absorbed to the outer surface of the absorber pipe after reflection in the mirror is as follows [18]:

$$
d \dot{Q}_{\mathrm{in}, 1}=I_{b} \rho \gamma(\tau a)_{b}\left(W-D_{O}\right) d x .
$$

In the equation above, $\rho$ is mirror reflection, $\gamma$ is concentrator gain coefficient due to concentrator optical losses, $T_{\tau}$ is radiation transmission coefficient of glass coating, and $a$ is the absorption coefficient of the outer surface of the pipe.

$(\tau a)_{b}$ is the product of the transmittance and absorption coefficients of the receiving set (metal pipe and glass coating), and the index $b$ means the corresponding value of these coefficients for the black body. The value of all the introduced coefficients is between zero and one.

Another part of the sunlight that is directly absorbed by the absorber pipe itself is calculated as follows:

$$
d \dot{Q}_{\mathrm{in}, 2}=I_{b}(\tau a)_{b} D_{O} d x .
$$

On the other hand, due to the difference between the temperature of the outer surface of the absorber pipe and the ambient temperature, part of the absorbed heat is transferred from the outer surface of the pipe to the environment in the form of radiation, convection, and heat conduction, which is considered as collector heat loss. This heat loss occurs with the calcite coefficient of heat transfer $U_{I}$. Therefore, the heat released from the above control volume is as follows:

$$
d \dot{Q}_{\text {out }}=U_{I} \pi D_{O}\left(T_{P}-T_{a}\right) d x .
$$

Therefore, the useful heat absorbed by the receiver is obtained by writing the energy balance equation:

$$
d \dot{Q}_{u}=d \dot{Q}_{\mathrm{in}, 1}+d \dot{Q}_{\mathrm{in}, 2}-d \dot{Q}_{\text {out }} .
$$

The optical efficiency of the collector is always the ratio of the radiation flux absorbed by the receiver to the radiation flux entering the collector. Therefore, the optical efficiency of the collector can be calculated as follows [20]:

$$
\eta=\frac{S}{I_{b}} .
$$

2.3. Useful Absorbed Heat. The temperature at which the fluid enters the collector and the ambient temperature are used to obtain the useful absorbed heat.

$$
F^{\prime}=\frac{1}{U_{I}\left[1 / U_{I}+1 / U_{C}\right]} .
$$




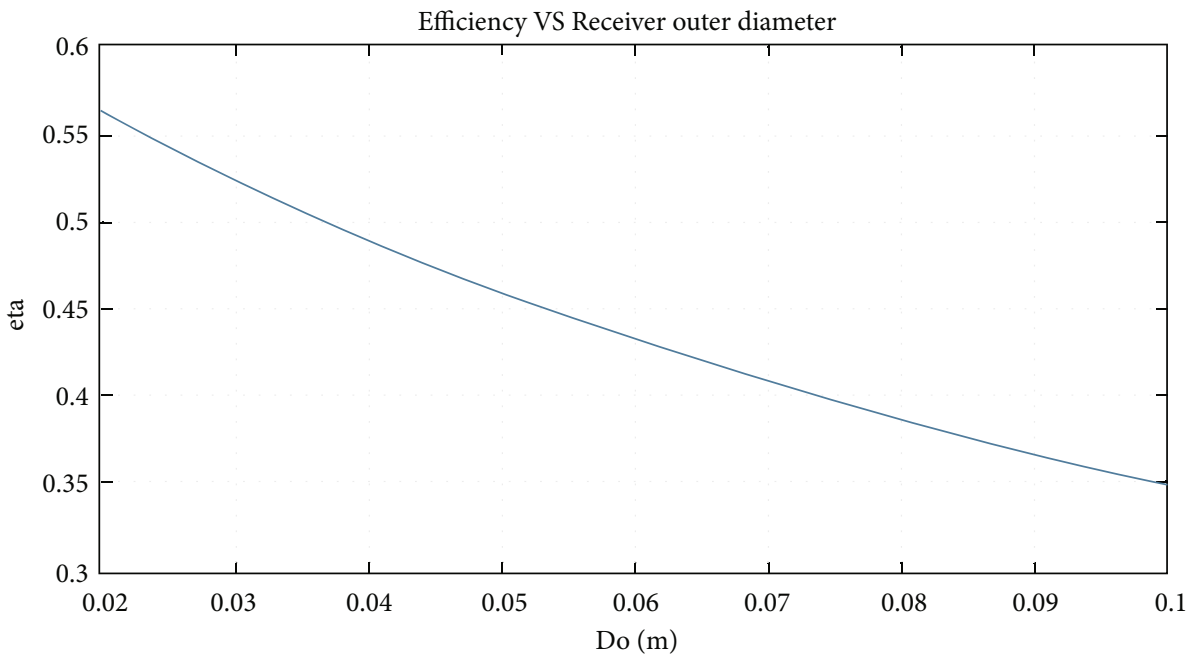

FIgURE 3: Changes in the efficiency of the absorber pipe by the outer diameter.

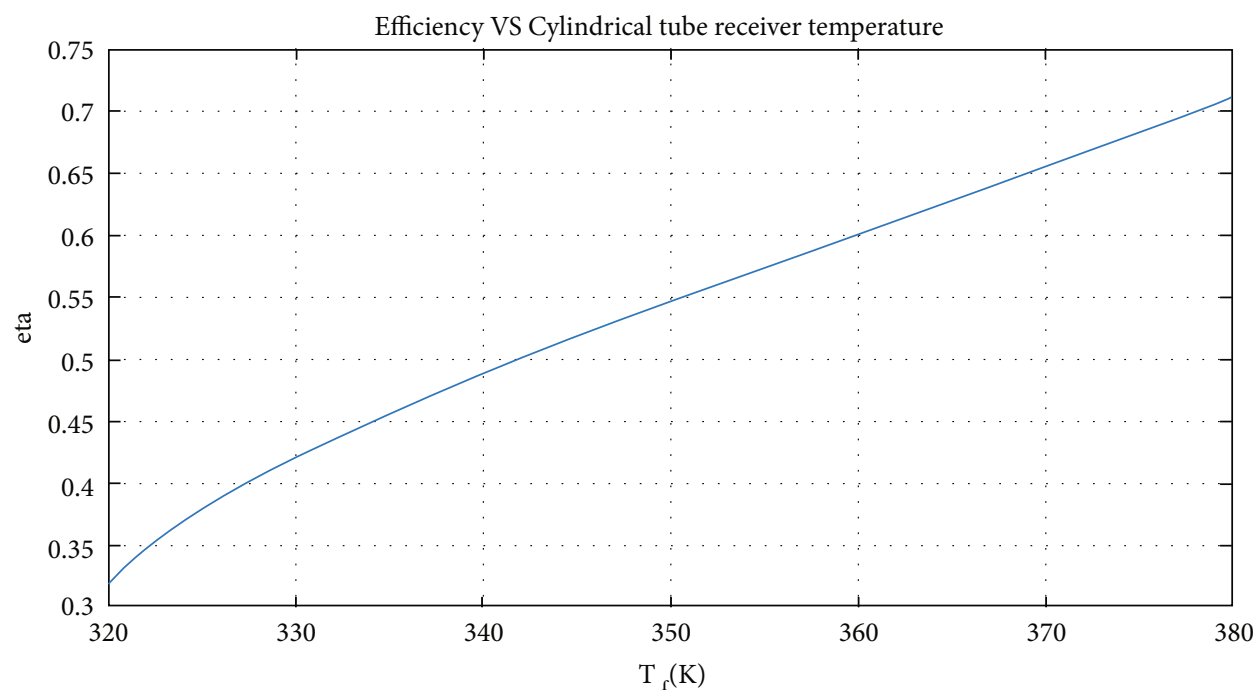

FIGURE 4: Changes in the efficiency of the absorber pipe by the temperature of its receiver.

$T$ is the local temperature of the fluid, and $F^{\prime}$ is the collector efficiency coefficient. The $U_{I}$ and $U_{C}$ heat transfer coefficients are both defined based on the outer surface of the receiver pipe. On the other hand, due to the fact that the temperature of the fluid increases by $d T$, then [18-20]

$$
d \dot{Q}_{u}=\dot{m} C_{P} d T
$$

So the total useful heat absorbed by the fluid is obtained as follows:

$$
\dot{Q}_{u}=\dot{m} C_{P}\left(\frac{C S}{U_{I}}+T_{a}-T_{\text {in }}\right)\left[1-\exp \left(-\frac{F, U_{I} \pi D_{O} x}{\dot{m} C_{P}}\right)\right]
$$

According to the useful absorbed heat and the total radiant energy that entered into the concentrator, the instantaneous thermal efficiency of the collector can be obtained:

$$
\eta_{I}=\frac{\dot{Q}_{u}}{I_{b} A_{C}}
$$

2.4. Exergy Balance for Solar Collector. Input exergies include solar radiation exergy and fluid flow exergy. Part of the sun's radiation exergy is transferred to the moving fluid; thus, the output flow exergy increases.

Input exergy: collector input exergy consists of two parts. One is the radiant exergy of the sun, and the other is the exergy of the incoming fluid, represented by $E_{(i, t h)}^{\prime}$ and $E_{(i, f)}^{\prime}$ , respectively.

Input radiative exergy: input radiative exergy is obtained from the sun due to the optical efficiency of concentrator and the temperature difference between the sun and the 


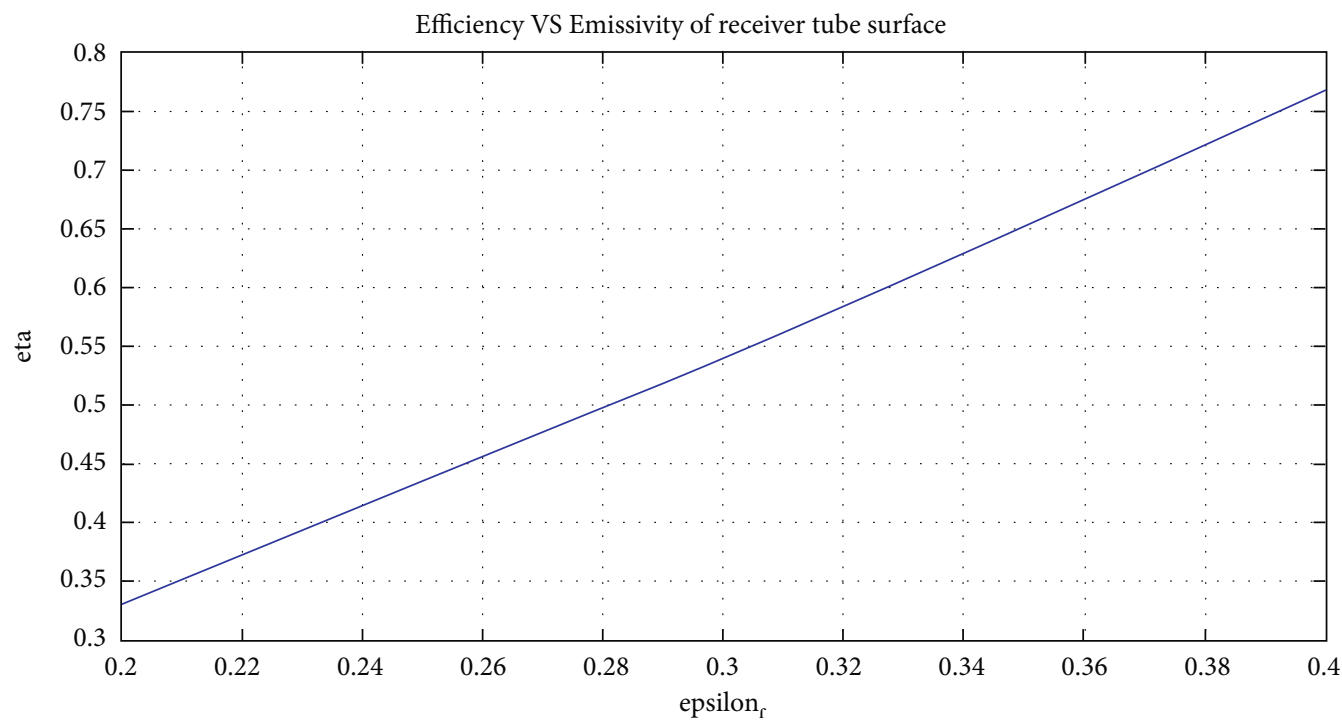

FIgURE 5: Changes in the efficiency of the absorber pipe by its emissivity coefficient.

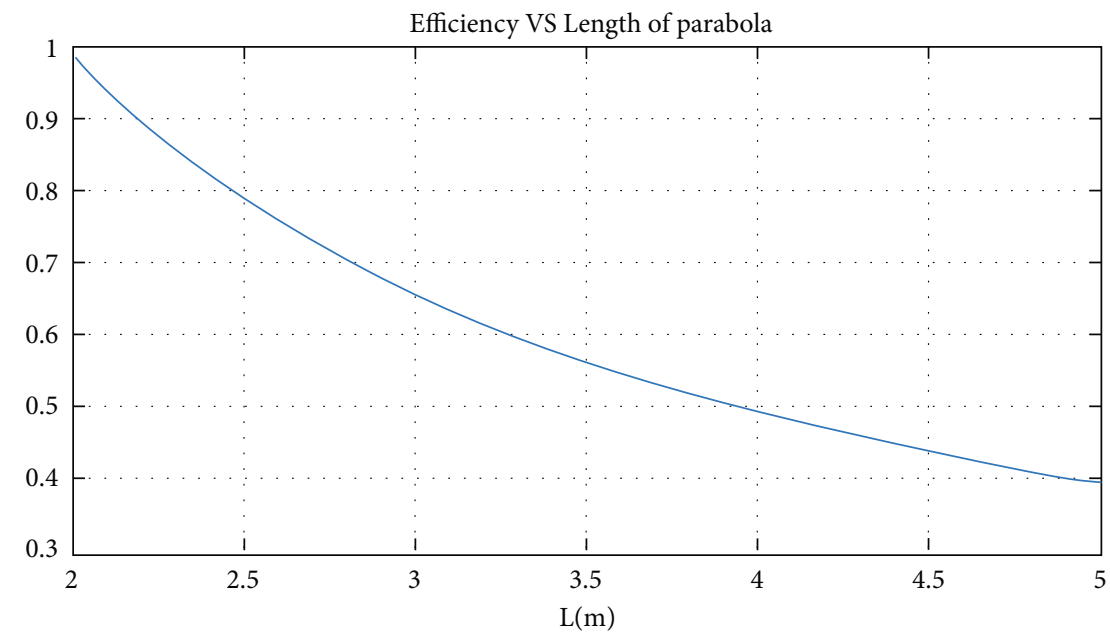

Figure 6: Changes in the efficiency of the absorber pipe by the length of it.

environment. $T_{b}$ is the intensity of sunlight, $\eta_{o}$ is the optical efficiency of the concentrator, and all the radiation absorbed to the outer surface of the absorber pipe is $I_{b} A_{c} \eta_{o}$, so this exergy can be obtained as follows [9]:

$$
E_{i, t h}^{\cdot}=I_{b} A_{c} \eta_{o}\left(1-\frac{T_{a}}{T_{s}}\right)
$$

In another equation, the input radiative exergy can be written as follows:

$$
\dot{E_{i, t h}}=\dot{Q}\left[1-\frac{4}{3}\left(\frac{T_{a}}{T_{s}}\right)+\frac{1}{3}\left(\frac{T_{a}}{T_{s}}\right)^{4}\right] .
$$

$T_{s}$ is the temperature of the sun, equal to 5762 degrees
Kelvin. The phrase inside the bracket is known as the Petela efficiency and is denoted by $\eta_{p}$. Therefore, the exergy of the solar input radiation exergy is obtained as follows:

$$
E_{i, t h}^{\cdot}=I_{b} A_{c} \eta_{o} \eta_{p}
$$

Inlet fluid flow exergy: to obtain the inlet fluid flow exergy, exergy must first be obtained per unit mass of the material, which for an incompressible material is as follows:

$$
e=\left(h-h_{o}\right)-T_{a}\left(s-s_{a}\right)=C_{p}\left(T-T_{a}-T_{a} \ln \frac{T}{T_{a}}\right)+\frac{\Delta P}{\rho} .
$$

In this equation, $\Delta P$ is the difference between the 


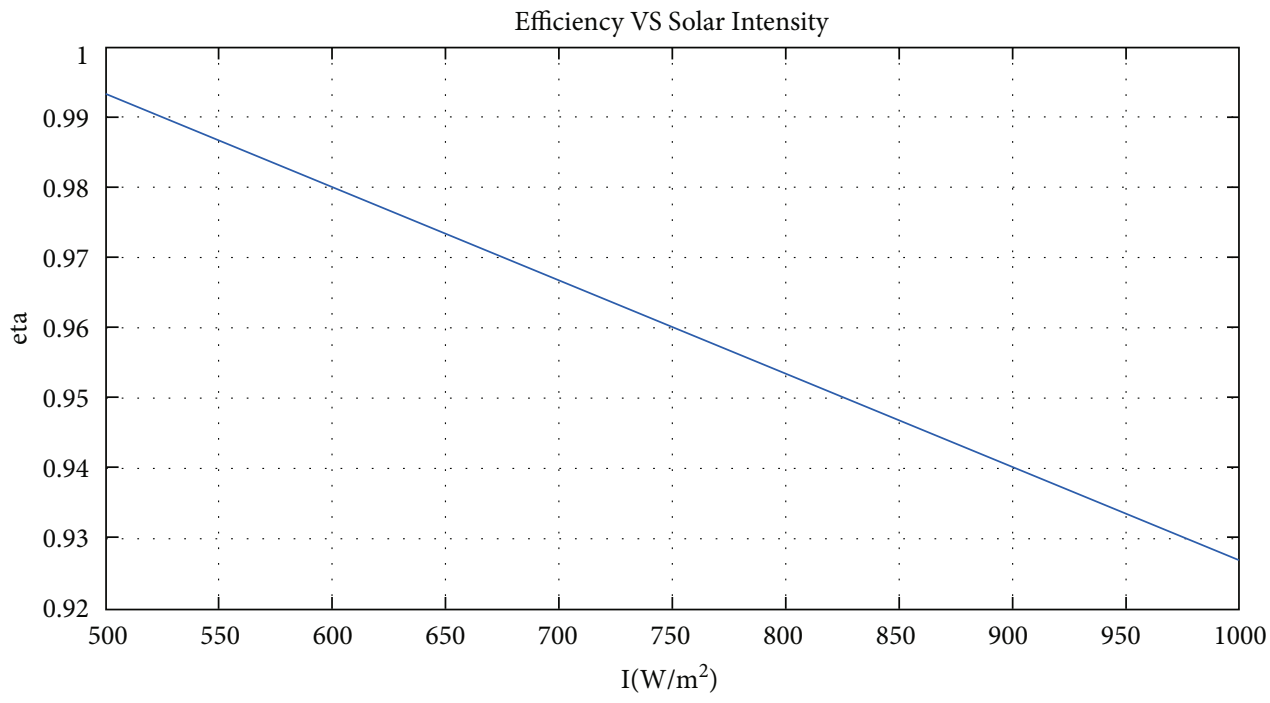

FIgURE 7: Changes in the efficiency of the absorber pipe by the intensity of radiation.

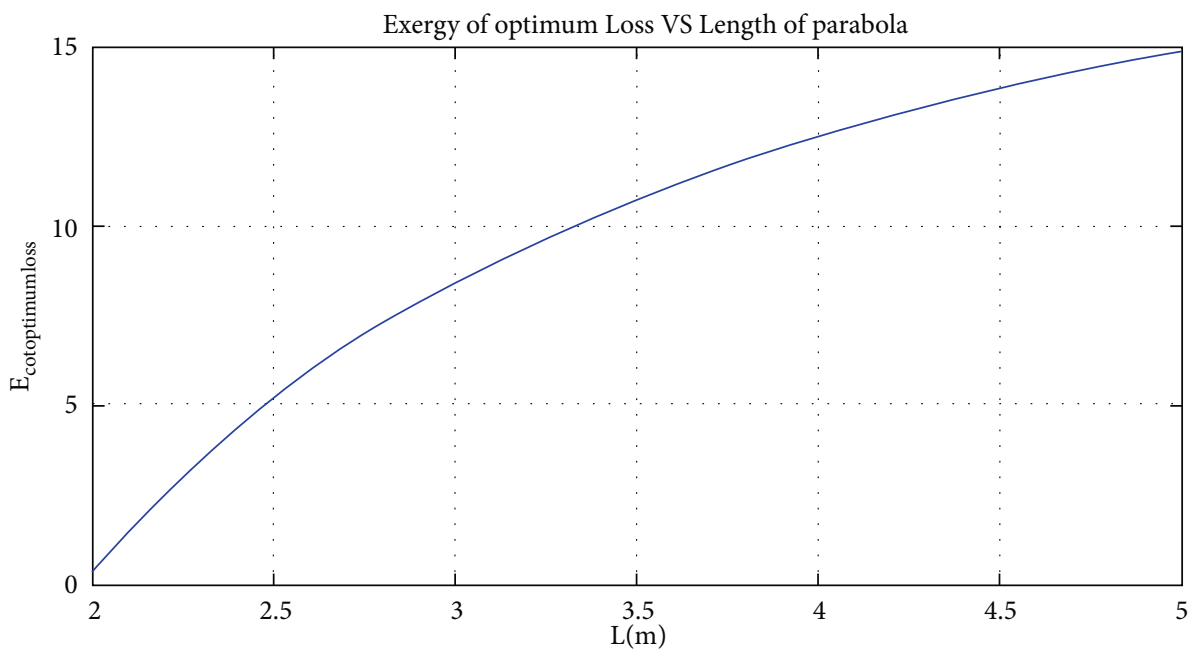

Figure 8: Changes of optimal loss of exergy by length of absorber pipe.

pressure the fluid and the environment. Using Equation (19) and ignoring the velocity and height of the fluid, the inlet fluid flow exergy is obtained as follows:

$$
\dot{E_{i, f}}=C_{p} \dot{m}\left(T_{\mathrm{in}}-T_{a}-T_{a} \ln \frac{T_{\mathrm{in}}}{T_{a}}\right)+\frac{\dot{m} \Delta P_{\mathrm{in}}}{\rho} .
$$

$\Delta P_{\text {in }}$ is the difference between the fluid pressure at the inlet and the ambient pressure. The sum of the radiative and the fluid flow exergies gives the total input exergy [9-20]:

$$
\dot{E_{I}}=\dot{E_{i, f}}+E_{i, t h}^{\cdot}
$$

Stored exergy: the stored exergy for steady state is zero, so

$$
\dot{E}_{I}=0 \text {. }
$$

Output exergy: the output exergy from the collector only includes the exergy of the fluid flow out of the collector and is similar to the input exergy of the flow [9-18]:

$$
\dot{E_{O}}=-C_{p} \dot{m}\left(T_{\text {out }}-T_{a}-T_{a} \ln \frac{T_{\text {out }}}{T_{a}}\right)-\frac{\dot{m} \Delta P_{\text {out }}}{\rho} .
$$

Leakage exergy: collector leakage is thermal only. The amount of leakage is the amount of heat loss from the collector that occurs between the surface temperature of the receiver and the ambient temperature:

$$
\dot{E}_{I}=-U_{I} A_{I}\left(T_{P}-T_{a}\right)\left(1-\frac{T_{a}}{T_{p}}\right) .
$$

$A_{I}$ is the outer surface of the absorber pipe. 


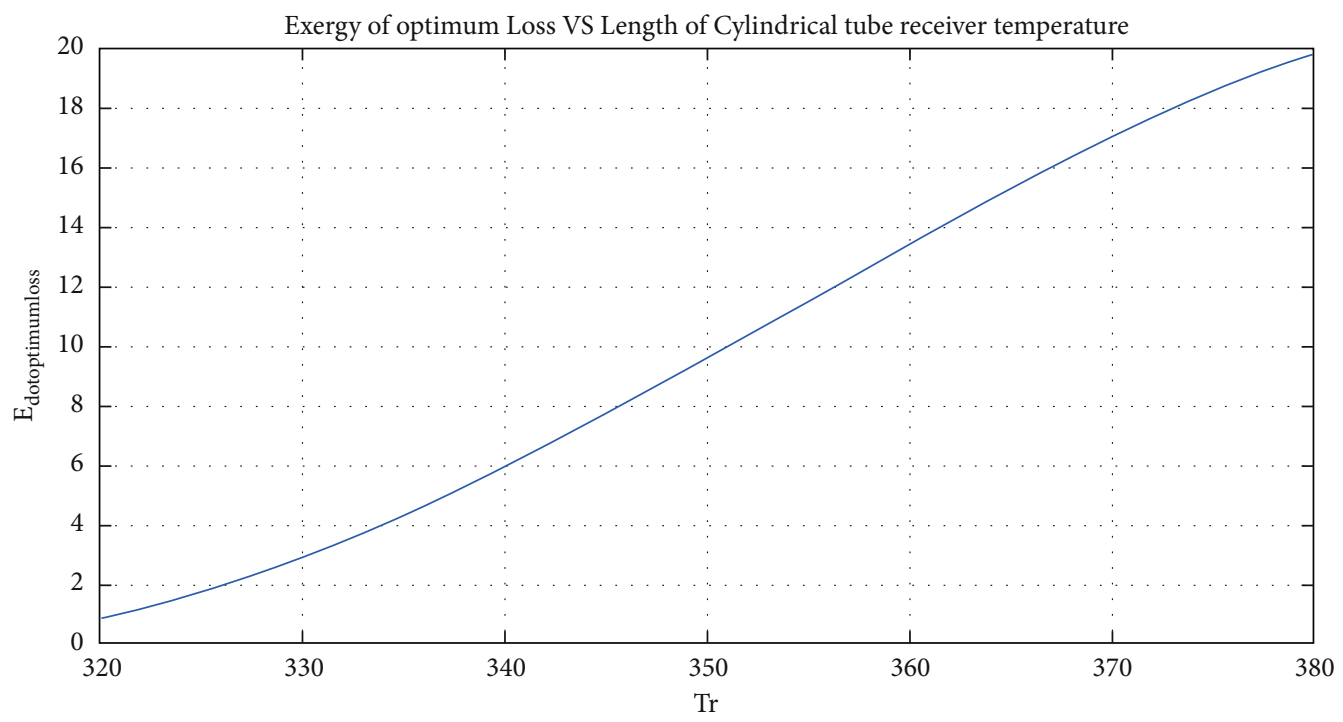

Figure 9: Changes of optimal loss of exergy by absorber pipe receiver temperature.

Destroyed exergy: destroyed exergy in the collector consists of three parts: first, destroyed exergy due to fluid pressure drop in the pipe; second, destroyed exergy due to the difference between the temperature of the sun and the surface of the receiver pipe; and third, destroyed exergy due to the difference in the receiver surface temperature with fluid temperature, each of which is described as follows.

Destroyed exergy due to pressure drop: to calculate this destroyed exergy, the difference in entropy produced due to pressure drop must be determined. The difference in entropy produced due to pressure drop can be written [9-20]:

$$
\dot{E}_{d, \Delta P}=-T_{a} \frac{\dot{m} \Delta P}{\rho} \frac{\operatorname{Ln}\left(T_{\text {out }} / T_{\text {in }}\right)}{T_{\text {out }}-T_{\text {in }}} .
$$

In the above equation, $\Delta P$ is the pressure difference between the inlet and outlet of the fluid. It should be noted that exergy due to pressure drop is very small and is often omitted in exergy analysis.

Destroyed exergy due to absorption of solar radiation: this destroyed exergy is due to the difference between the temperature of the sun and the surface of the receiver. Since the amount of heat absorbed to the surface of the receiver is $I_{b} A_{c} \eta_{o}$, its value is as follows [18]:

$$
\dot{E}_{d, \mathrm{abs}}=-T_{a} I_{b} A_{c} \eta_{o}\left(\frac{1}{T_{P}}-\frac{1}{T_{s}}\right) .
$$

Destroyed exergy due to thermal conductivity: this destroyed exergy is due to the difference between the temperature of the receiver surface and the temperature of the fluid. Given that the heat transfer takes place between the temperature of outer surface of the receiver, i.e., $T_{P}$, and the fluid with the local temperature $T$, so [9-20]

$$
\dot{E}_{d, \text { cond }}=-C_{P} \dot{m} T_{a}\left(\operatorname{Ln} \frac{T_{\text {out }}}{T_{\text {in }}}-\frac{T_{\text {out }}-T_{\text {in }}}{T_{P}}\right) .
$$

The exergy efficiency for a solar collector is gained exergy to the input radiative exergy. Therefore, the exergy efficiency is obtained as follows [18-20]:

$$
\begin{aligned}
\eta_{E}= & 1-\left[\left(1-\eta_{o}\right)+\frac{\eta_{o} T_{a}}{\eta_{p}}\left(\frac{1}{T_{P}}-\frac{1}{T_{s}}\right)+\frac{U_{I} A_{I}\left(T_{P}-T_{a}\right)}{I_{b} A_{c} \eta_{p}}\right. \\
& \cdot\left(1-\frac{T_{a}}{T_{p}}\right)+\frac{C_{P} \dot{m} T_{a}}{I_{b} A_{c} \eta_{p}}\left(\operatorname{Ln} \frac{T_{\text {out }}}{T_{\text {in }}}-\frac{T_{\text {out }}-T_{\text {in }}}{T_{P}}\right) \\
& \left.+\frac{T_{a}}{I_{b} A_{c} \eta_{p}} \frac{\dot{m} \Delta P}{\rho} \frac{\operatorname{Ln}\left(T_{\text {out }} / T_{\text {in }}\right)}{T_{\text {out }}-T_{\text {in }}}\right] .
\end{aligned}
$$

\section{Results}

3.1. Validation. In order to better benefit from the results obtained in the research, first, a validation has been performed. For this purpose, Reference [9] is used, which can be seen in Table 1 .

Figure 3 shows the changes in the efficiency of the absorber pipe by its outer diameter. The outer diameter simulation was performed in the range of $2 \mathrm{~cm}$ to $10 \mathrm{~cm}$. According to the chart, with increase of the outer diameter of the absorber pipe, its efficiency decreases almost linearly. According to the diagram, if the outer diameter increases by $8 \mathrm{~cm}$, the efficiency decreases by about 0.2 . This indicates that the outer diameter affects the efficiency strongly.

Figure 4 shows the changes in the efficiency of the absorber pipe by the temperature of its receiver. In this simulation, the temperature is changed from $320 \mathrm{~K}$ to $380 \mathrm{~K}$. As shown in the chart below, as the temperature changes, the efficiency increases first nonlinearly and then linearly. 
According to the chart, for temperature changes of $18.75 \%$, it increases to 0.38 . However, reaching a temperature of $380 \mathrm{~K}$ is not easy and in many cases will be uneconomical, but in general, the temperature parameter also changes the efficiency significantly.

Figure 5 shows the efficiency changes by the emissivity coefficient of the absorber pipe. In this simulation, the emissivity coefficient increases from 0.2 to 0.4 . As shown in the following figure, with an increasing emissivity coefficient, the efficiency increases linearly. In fact, by increasing the emissivity coefficient, the ability of the absorber pipes to transfer heat and reduce the temperature of the system increases, and therefore, the efficiency increases. However, increasing the emissivity coefficient is very difficult because it depends on the structural properties of the material, and it takes years for the emissivity coefficient of a material to increase by 0.01 .

In Figure 6, the effect of the length of the absorber pipe on the efficiency is shown. In this simulation, the length of the absorber pipe changes from 2 to $5 \mathrm{~m}$. According to the diagram below, the efficiency of the absorber pipe decreases nonlinearly with increasing length. The reason is the longer the pipe length, the more drops due to the friction as well as the energy loss which all lead to the lower efficiency. However, the length of the pipe is determined by the amount of energy required, and therefore, the efficiency does not reach high values.

In Figure 7, the effect of solar radiation intensity on efficiency is investigated. In the simulation, the intensity of solar radiation has changed from 500 to $1000 \mathrm{~W} / \mathrm{m}^{2}$. The reason is that with increasing radiation intensity due to the emissivity coefficient, more energy is lost, and as a result, the efficiency decreases. As in the following figure, the efficiency at a radiation intensity of $500 \mathrm{~W} / \mathrm{m}^{2}$ is very high. This amount of radiation occurs at the first and last hours in the day. However, the intensity of $500 \mathrm{~W} / \mathrm{m}^{2}$ cannot handle a solar cooling or heating system in any way. Therefore, higher levels of radiation intensity should be considered by accepting a reduction in efficiency.

3.2. Exergy Analysis Results. The following figures show the results of the exergy analysis section. Figure 8 shows the chart of the changes of optimal loss of exergy by the length of the absorber pipe. According to the diagram below, with increasing length of the absorber pipe, the loss exergy increases exponentially. Considering the trend of the graph, the amount of exergy will probably converge to a constant value. In this chart, the length of the pipe has changed from 2 to $5 \mathrm{~m}$.

As seen in Figure 8, the more the length of the absorber increases, the energy efficiency increases so that for the absorber length of $5 \mathrm{~m}$, efficiency will be $15 \%$; the relationship between temperature of absorber tube and efficiency is seen in Figure 9.

As seen in Figure 9, as the length of the absorber tube increases, the exergy efficiency will increase so that for a temperature of $380^{\circ} \mathrm{C}$, the exergy efficiency will be $20 \%$.

\section{Conclusion}

The use of solar energy is one of the common ways to generate electricity combined with thermal energy, which makes use of this energy. Due to the heat exchange to the environment from the fluid and the increase in solar collector losses, the efficiency of this technology decreases. Utilization of renewable energies is increasing daily, and the most common type of renewable energy is solar energy which is available in all areas of Earth. Thermal generation by solar absorbers is one of the most common techniques of utilization of solar energy. A high amount of energy for thermal generation in residential buildings is used. Therefore, thermal energy through the sun is an appropriate solution to decrease dependency of the building section on fossil energy; hence, in this research, modeling of a linear parabolic collector is conducted with the aim of investigating the exergy efficiency considering physical factors. Among those significant results, the following cases could be mentioned:

(1) Increasing the length of the absorber pipe has an adverse effect on the efficiency of the absorber pipe. With increasing length of the absorber pipe, its efficiency decreases nonlinearly

(2) As the emissivity coefficient increases, the efficiency increases due to increased heat transfer. This parameter cannot be a suitable parameter to increase efficiency because it depends on the material and its molecular structure

(3) As the diameter of the pipe increases, the amount of energy loss due to increased friction increases and the efficiency decreases

(4) As the intensity of the radiation increases, the amount of energy loss increases and the efficiency decreases. Because the solar energy is a renewable source and always available during the day, high levels of radiation intensity should be considered to increase energy, and the issue of efficiency for this parameter is the next priority

(5) Increasing the temperature of the absorber pipe receiver increases the efficiency. However increasing the temperature itself requires energy, and the temperature cannot be increased too much

(6) As the length and diameter of the pipe increase, the optimal loss of exergy increases

\section{Nomenclature}

$\begin{array}{ll}a: & \text { Length }(\mathrm{m}) \\ \varphi: & \text { Angle }\left({ }^{\circ}\right) \\ L: & \text { Length }(\mathrm{m}) \\ D: & \text { Diameter }(\mathrm{m}) \\ c: & \text { Area }\left(\mathrm{m}^{2}\right) \\ W: & \text { Width }(\mathrm{m}) \\ T: & \text { Temperature }(\mathrm{K}) \\ I: & \text { Radiation }\left(\mathrm{W} / \mathrm{m}^{2}\right)\end{array}$


$\rho: \quad$ Reflection

$\gamma$ : Concentrator gain coefficient

$F^{\prime}$ : Collector efficiency coefficient

M: Mass flow

$U$ : Heat transfer $\left(\mathrm{W} / \mathrm{m}^{2} \cdot \mathrm{K}\right)$

E: exergy

$P$ : Pressure $(\mathrm{kPa})$.

\section{Subscripts}

out: Outlet

in: Inlet

th: Thermal

f: $\quad$ Fluid

aux: Auxiliary.

\section{Data Availability}

The data used to support the findings of this study are included within the article.

\section{Conflicts of Interest}

The authors declare that they have no conflicts of interest.

\section{References}

[1] R. Alayi and H. Rouhi, "Techno-economic analysis of electrical energy generation from urban waste in Hamadan, Iran," International Journal of Design \& Nature and Ecodynamics, vol. 15, no. 3, pp. 337-341, 2020.

[2] H. Khalili, A. Arash, and R. Alayi, "Simulation and economical optimization hybrid system PV and grid in Ardabil city," Journal of Current Research in Science, vol. 3, no. 5, p. 83, 2015.

[3] M. A. Ehyaei, A. Ahmadi, M. el Haj Assad, and T. Salameh, "Optimization of parabolic through collector (PTC) with multi objective swarm optimization (MOPSO) and energy, exergy and economic analyses," Journal of Cleaner Production, vol. 234, pp. 285-296, 2019.

[4] Y. Khanjari, A. Kasaeian, F. Pourfayaz, and R. Alayi, "Performance evaluation of liquid-cooled photovoltaic system using numerical method," Advances in Science and Technology Research Journal, vol. 10, no. 32, pp. 184-192, 2016.

[5] G. M. Patel, H. S. Parmar, and P. T. Deota, "Improved photostabilization of chlorpyrifos insecticide with novel benzil derivatives," Chemical Methodologies, vol. 3, no. 4, pp. 481-493, 2019.

[6] S. Naeimi Dizajeyekan, G. Shahgholi, and A. Rezvanivande Fanayi, "The influence of the pipe's material and the mass flow rate on the pressure drop and velocity variation during pneumatic conveying of wheat using computational fluid dynamics," International Journal of Advanced Biological and Biomedical Research, vol. 3, no. 2, pp. 124-133, 2015.

[7] R. Alayi, F. Zishan, M. Mohkam, S. Hoseinzadeh, S. Memon, and D. A. Garcia, "A sustainable energy distribution configuration for microgrids integrated to the national grid using back-to-back converters in a renewable power system," Electronics, vol. 10, no. 15, p. 1826, 2021.

[8] K. Bogarrasa and M. Khlifa, "Effect of pure and binary azeotropic fluids on heat pipes performance," Advanced Journal of Chemistry-Section A, vol. 3, no. 4, pp. 442-453, 2020.
[9] R. Alayi, A. Kasaeian, and F. Atabi, "Optical modeling and optimization of parabolic trough concentration photovoltaic/thermal system," Environmental Progress \& Sustainable Energy, vol. 39, no. 2, article e13303, 2020.

[10] M. Sajjadnejad, S. M. S. Haghshenas, V. Tavakoli Targhi, H. Ghafarian Zahmatkesh, and M. Naeimi, "Utilization of sustainable energies for purification of water," Advanced Journal of Chemistry-Section A, vol. 3, no. 4, pp. 493-509, 2020.

[11] R. Alayi, R. Kumar, S. R. Seydnouri, M. H. Ahmadi, and A. Issakhov, "Energy, environment and economic analyses of a parabolic trough concentrating photovoltaic/thermal system," International Journal of Low-Carbon Technologies, vol. 16, no. 2, pp. 570-576, 2021.

[12] R. Alayi, M. H. Ahmadi, A. R. Visei, S. Sharma, and A. Najafi, "Technical and environmental analysis of photovoltaic and solar water heater cogeneration system: a case study of Saveh city," International Journal of Low-Carbon Technologies, vol. 16, no. 2, pp. 447-453, 2021.

[13] O. O. Amusan, H. Louis, S. U. Zafar, A. T. Hamzat, and D. M. Peter, "Different interface engineering in organic solar cells: a review," Chemical Methodologies, vol. 3, no. 4, pp. 425-441, 2019.

[14] O. M. Opeyemi, H. Louis, C. I. Oparab, O. O. Funmilayo, and T. O. Magu, "Porphyrin and phthalocyanines-based solar cells: fundamental mechanisms and recent advances," Advanced Journal of Chemistry-Section A, vol. 2, no. 1, pp. 21-44, 2019.

[15] S. Zuhur, İ. Ceylan, and A. Ergün, "Energy, exergy and environmental impact analysis of concentrated PV/cooling system in Turkey," Solar Energy, vol. 180, pp. 567-574, 2019.

[16] R. Alayi, N. Khalilpoor, S. Heshmati, A. Najafi, and A. Issakhov, "Thermal and environmental analysis solar water heater system for residential buildings," International Journal of Photoenergy, vol. 2021, 9 pages, 2021.

[17] A. Peinado Gonzalo, A. Pliego Marugán, and F. P. García Márquez, "A review of the application performances of concentrated solar power systems," Applied Energy, vol. 255, article 113893, 2019.

[18] O. Chakraborty, B. Das, R. Gupta, and S. Debbarma, "Heat transfer enhancement analysis of parabolic trough collector with straight and helical absorber tube," Thermal Science and Engineering Progress, vol. 20, article 100718, 2020.

[19] H. Zhai, Y. J. Dai, J. Y. Wu, and R. Z. Wang, "Energy and exergy analyses on a novel hybrid solar heating, cooling and power generation system for remote areas," Applied Energy, vol. 86, no. 9, pp. 1395-1404, 2009.

[20] A. A. A. Arani and F. Monfaredi, "Energy and exergy analyses of nanofluid-filled parabolic trough solar collector with acentric absorber tube and insulator roof," Journal of Thermal Analysis and Calorimetry, vol. 145, no. 3, pp. 787-816, 2021.

[21] V. Thirunavukkarasu, M. Sornanathan, and M. Cheralathan, "An experimental study on energy and exergy performance of a cavity receiver for solar parabolic dish concentrator," International Journal of Exergy, vol. 23, no. 2, pp. 129-148, 2017.

[22] S. K. Verma, N. K. Gupta, and D. Rakshit, “A comprehensive analysis on advances in application of solar collectors considering design, process and working fluid parameters for solar to thermal conversion," Solar Energy, vol. 208, pp. 11141150, 2020.

[23] J. Sun, Z. Zhang, L. Wang, Z. Zhang, and J. Wei, “Comprehensive review of line-focus concentrating solar thermal 
technologies: parabolic trough collector (PTC) vs linear Fresnel reflector (LFR)," Journal of Thermal Science, pp. 1-28, 2020.

[24] A. Ullah, A. Mushtaq, R. A. Qamar, and Z. U. Ali, "Performance analysis and modeling of parabolic trough based concentrated solar facility using different thermal fluid mediums," Journal of Engineering Research, vol. 9, no. 1, 2021.

[25] Y. Cao, H. Ayed, M. Hashemian, A. Issakhov, and M. Waehayee, "Thermal/frictional performance of spiral pipe with ring-shape depression used as in-pond heat exchanger," Solar Energy, vol. 224, pp. 742-756, 2021.

[26] C. Liu, M. Hashemian, A. Shawabkeh et al., "CFD-based irreversibility analysis of avant-garde semi-O/O-shape grooving fashions of solar pond heat trade-off unit," Renewable Energy, vol. 171, pp. 328-343, 2021.

[27] S. Jafary, S. Khalilarya, A. Shawabkeh, M. Wae-hayee, and M. Hashemian, "A complete energetic and exergetic analysis of a solar powered trigeneration system with two novel organic Rankine cycle (ORC) configurations," Journal of Cleaner Production, vol. 281, article 124552, 2021. 